\title{
Canada can release pandemic vaccine earlier if necessary, chief public health officer says
}

Published at www.cmaj.ca on Sept. 30.

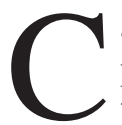

anada has put an emergency process in place to release the pandemic (H1N1) 2009 influenza vaccine before November if necessary, says Dr. David ButlerJones, the country's chief public health officer.

Although vaccine manufacturer GlaxoSmithKline Inc. expects to have initial lots ready for delivery in October, the Public Health Agency of Canada (PHAC) and Health Minister Leona Aglukkaq have previously said Canadians won't begin to receive the vaccine until the first week in November. That's because PHAC is waiting for Health Canada to review the results of clinical trials that the federal government is funding concerning the vaccine's efficacy among Aboriginals and children, as well as results from larger international studies on similar pandemic vaccines.

Some infectious diseases experts and critical care doctors have expressed concern about the timing (CMAJ 2009;181:253-4). They're worried that if the virus picks up speed and the influenza season begins earlier than usual, Canada will lose precious time in its drive to slow the spread of infection.

But PHAC is prepared to change its plans and ask Aglukkaq to release the vaccine without waiting for the clinical studies if its risk-benefit model indicates the need for an earlier roll out, Butler-Jones told CMAJ during an editorial round-table discussion. "If incidence increases or severity increases or there's a great public health risk, then the risk-benefit changes. Then we have access to an emergency access process."

Unlike seasonal influenza vaccines, the pandemic vaccine is not licensed through Health Canada's customary regulatory process. So Aglukkaq can

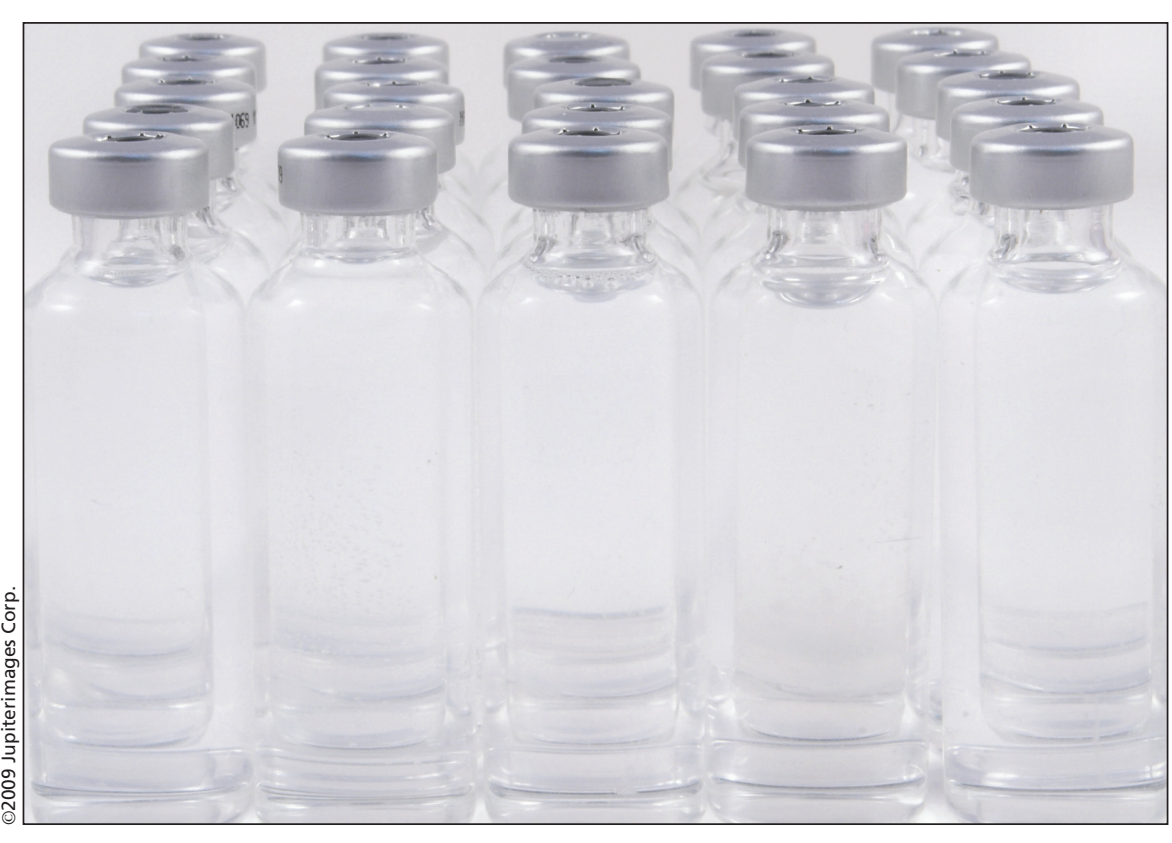

Canadian health care professionals should be more willing to tap the national stockpile of pandemic (H1N1) 2009 flu vaccine, says Dr. David Butler Jones, Canada's chief public health officer. "We're the ones that kill our patients."

sign a ministerial order to authorize its release, if recommended, Butler-Jones said. "If the issue of severity and other things comes together ... then potentially we can go earlier."

Even if that happens, PHAC will continue to monitor adverse events through reports from doctors and hospitals, Butler-Jones says.

As well, Canada will conduct large postmarket surveillance studies of the first 100000 people vaccinated, says Dr. Theresa Tam, director general for PHAC's Centre for Emergency Preparedness and Response.

However, she acknowledged that the program will likely not find extremely rare adverse events, "like something that occurs once in a million."

Butler-Jones appeared confident there will be few such complications.

"We have a long track record for influenza vaccines with varied antigens and with the adjuvants," he said. "We look for surprises, but there have been few surprises, which is why the Americans have without any evidence from trials, (already) licensed the vaccine."

If Canadians do experience adverse events, the federal government is not considering a no-fault compensation scheme, he said. Quebec is the only jurisdiction that offers such a plan for adverse events resulting from immunizations.

But like other G-8 governments, Canada has agreed to protect GlaxoSmithKline in case of potential lawsuits, because the vaccine is not licensed under the usual regulatory process, Butler-Jones says. "If there's a vaccine problem, as opposed to a malpractice problem, then the company is indemnified."

In practice, that means patients who had a bad reaction to the vaccine would have to sue. If they won, any damages a court awarded would be collected from the federal government financed by the taxpayer — rather than from the manufacturer. 
One of the challenges PHAC faces will be to persuade health care professionals and workers to get immunized with the pandemic (H1N1) 2009 vaccine, Butler-Jones acknowledged. "It's always a challenge. ... There's some attitudinal issues that we have to address."

But he points out that most health care associations view having their members vaccinated as a duty of care - as does he.

"We're the ones that kill our patients," he said bluntly, referring to health professionals who inadvertently spread the virus. "We take it into the nursing home. So it's not for the protection of me, it's for the protection of my patients."

Adding that he personally will get both the seasonal and pandemic vaccines, Butler-Jones says convincing Canadians to be vaccinated will also be a challenge. But he indicated the federal government plans to roll out national television and radio ads urging all Canadians to take up the vaccine once it's available.

Canada's decision to add an adjuvant to the vaccine in order to make more doses available is also intended to stimulate a more robust immune response in people who are vaccinated, said Butler-Jones and Tam.

As well, the vaccine, should provide some immunity even if the virus mutates, Butler-Jones says. "It is a much better vaccine, and it appears to protect against drift. So if there is a change in the virus ... it provides cross-protection." - Laura Eggertson, Ottawa, Ont.

DOI:10.1503/cmaj.109-3065 